\title{
IDENTIFY SOME BIOLOGICAL CRITICAL CONTROL POINTS OF BARKI SHEEP PRODUCTION RAISED IN NORTH WESTERN DESERT OF EGYPT
}

\author{
Mona Mohammady I.
}

Desert research center, Animal Production and Poultry Division, Cairo, Egypt, Mathaf El-Matariya St. No. 1

Received: 18/5/2017

\section{SUMMARY}

The current research was conducted to highlight on some biological critical control points (CCPS) responsible for production in Barki sheep flocks. Quantify biological values (BVS) and economic values $(E V S)$ of the critical biological trait were also estimated. The sensitivity analysis was carried out to predict its potential economic response to proposed scenarios varying in biological parameters level and market prices. Data utilized in this study were 7300 accumulated records of Barki ewes collected over 37 successive breeding seasons of Barki sheep flock. Partial Least Squares regression (PLS) procedures as described by XLSTAT (2009) were applied. The obtained results indicated that lamb's growth rate (GR) was the most biological critical control point of Barki flock productivity. GR had a marked positive impact on kilograms of lambs weaned per ewe joined (KW/EJ) with biological value of $+548 \mathrm{gm}$. Lambs mortality rate (LMR) had negative effect on KW/EJ and declined KW/EJ by -143 gm. Growth rate had the highest positive EV per ewe and exceeded gross margin per ewe (GM/EJ) by LE +25 compared to base flock. LMR had negative EV of $L E-6$. GR considered a critical success factor in the revenues, while LMR had a severe negative impact on Barki sheep enterprise profitability. It could be concluded that GR and LMR are the biological CCPs for Barki flock productivity and profitability. Sensitivity analysis confirmed that, EVs of the studied CCPs were more sensitive to changes in concentrate feed mix costs and lambs mortality rate than the other proposed scenarios.

Keywords: Barki sheep, biological values, economic values, gross margin, critical control points.

\section{INTRODUCTION}

Small ruminants play an important role in feeding the rapidly expanding population under harsh environmental conditions, this due to their low feed requirements, short generation interval, faster growth rate and higher environmental adaptability compared to large ruminants (Tibbo et al. 2006). In Egypt, three main local sheep breeds are raised; Ossimi, Rahmani and Barki and amount up to 4.5 million (CAPMAS, 2015), which are distributed in different agroecological zones. Barki sheep is the dominant breed raised in the Western Desert, particularly in the North Western Coastal Zone and well adapted to the prevailing harsh conditions but with low productive performance. It rises mainly for lamb production with carpet wool production as a secondary product. Barki sheep enterprise has an important role in contributing to the food security as well as generating direct cash income for the people living in the desert provinces.

Improving biological and economical performance of Barki flocks are goals most producers aspire to. Improvement can be made by first establish a recommended biological criteria for judging the current production performance of the flock, and followed by identifying which biological critical control points (CCPs) of the production chain are most responsible for production performance and flock profitability. Knowing these CCPs allow producers to focus their management efforts on these points and assist them in decision making process. Furthermore, supporting the development of breeding objectives, which is generally, represents the first step in establishing structured breeding programs based on estimated economic values (EVs) of biological CCPs..

There are a few studies concern of identifying the biological CCPs of Barki sheep enterprise and its economic values. Therefore, the current research highlights some of biological CCPs most responsible for production and profitability of Barki sheep enterprise; quantify both biological and the economic values of each target biological trait. In addition, run sensitivity test to investigate their sensitivity and potential economic response to proposed scenarios varying in biological performance and market price indicators.

\section{MATERIALS AND METHODS}

\section{Data}

Flock biological data set utilized in this study were comprised of 7300 records of Barki ewes representing 2039 breeding ewes obtained from the accumulated records collected over 37 successive breeding seasons of Barki sheep flock (from 1972 to 2009). The current flock raised under semi-arid conditions at Maryout Research Station. This station is located in the North West of Nile Delta, $180 \mathrm{~km}$ from Cairo and belonging to the Desert Research Center. The biological record-keeping system of the studied flock included; a unique identification number for each ewe and her lambs, birth date of the lambs, sex and type of birth, weaning weight, monthly animal weight and pedigree. Disposed 
animals were recorded along with the date and cause of disposal.

\section{Flock management practices}

Sheep were kept in open shaded pens, provided with a source of fresh water available twice daily. Breeding rams and ewes were selected to join mating season once a year according to Barki breed phenotypic characteristics and biological performance. Flock performs controlled natural mating and lambing occurs throughout FebruaryMarch. Breeding ewes were allocated with fertile ram in the mating groups $(20-25$ ewes/group $)$. Feed was composed of concentrate feed mix (CFM) plus berseem (Trifolium alexandrinum) as a green fodder during the period from October to May, while the rest of the year berseem was replaced by berseem hay. In addition, rice or wheat straw was available all the year round. Two weeks prior the mating season an extra supplementary CFM of about $0.25 \mathrm{~kg} / \mathrm{head} /$ day was offered for flushing the ewes and also during late pregnancy and early lactation period. At lambing season, new born lambs were identified. Newborn weights were recorded within 24 hours of birth and bi-weekly till weaning at an average 3 months of age. Ewe lambs and ram lambs joined mating season for the first time at age of approximately 1.5 years.

\section{Statistical analysis:}

Least squares procedures as described by SAS (2004) were performed using a fixed effect linear model to estimate the means and standard deviation of kilograms of lambs weaned per ewe joined $(\mathrm{KW} / \mathrm{EJ})$ for the 37 breeding seasons of the studied Barki flock. The biological variables which suppose to be relevant to $\mathrm{KW} / \mathrm{EJ}$ were; number of ewes lambed per ewe joined (EL/EJ), number of lambs born per ewe lambed (LB/EL), kilograms of lambs born per ewe joined $(\mathrm{KB} / \mathrm{EJ})$, average birth weight (BWT), average weaning weight (WWT), lambs mortality rate up to weaning (LMR) and average growth rate from birth up to weaning age (GR). The following fixed effect linear model was adopted to estimate the above functional traits:

$$
\begin{aligned}
& \quad Y_{i j}=\mu+a_{i}+e_{i j} \\
& \text { Where: } \\
& Y_{i j}=\text { the observation, } \\
& \mu=\text { the overall mean, } \\
& a_{i}=\text { the effect due to } i^{\text {th }} \text { breeding season, } i=1,2 \text { up }
\end{aligned}
$$
to 37 ,

$\mathrm{e}_{\mathrm{ij}}=$ the random error, associated with the individual observation, assumed to be normally independently distributed with mean $=0$ and variance $=\partial^{2} \mathrm{e}$. The significant differences among means of biological traits were tested using Duncan's Multiple Range Test.

\section{Partial least squares regression:}

The goal from regression procedures of the present study is to find an efficient regression equation with high predictive power measured by $\mathrm{R}^{2}$. Thus, least squares means of the target biological variables derived from statistical analysis were preceded by Partial Least Squares Regression (PLS) procedures as described by XLSTAT (2009), 1.01 Software to; construct the correlation matrix among the studied biological variables, derive prediction equation for dependent (response) variable (KW/EJ) and identify variable importance for the prediction (VIP) to measure the relative importance of each considered biological traits. The current study included one biological dependent variable (KW/EJ) and seven biological independent (explanatory) variables (EL/EJ, LB/EL, KB/EJ, BWT, WWT, LMR, and GR).

\section{Bio-economic analysis: \\ Biological values:}

Kilograms of lambs weaned per ewe joined $(\mathrm{KW} / \mathrm{EJ})$ is considered a conclusive single criteria of biological performance of sheep flock, since it combines both ewe and ram fertility, as well as mortality and growth rate of lambs into one index (as suggested by Ahmed, 2008). Prediction equation generated from PLS procedures was applied to derive the expected values of $\mathrm{KW} / \mathrm{EJ}$ when biological traits increased by one unit ( $1 \%$ for traits measured in percentage and $10 \%$ for traits measured in gm), while keeping all the other biological variables at the existing mean values. Biological values $(\mathrm{BV})$ of the target traits were calculated by the differences between the actual value of the KW/EJ of the base flock and its expected value after increase each biological independent variable by one unit according to the following formula;

$\mathrm{BV}=$ predicted $(\mathrm{KW} / \mathrm{EJ})-$ base flock $(\mathrm{KW} / \mathrm{EJ})$. (1) Where: $\mathrm{BV}$; biological value, $\mathrm{KW} / \mathrm{EJ}$; kilograms of lambs weaned per ewe joined.

\section{Economic values:}

One of the useful tools for estimating economic values of biological traits is a bio-economic modeling which provides a very powerful tool to estimate the economic values of various biological traits. The collected financial data covered variable costs of; feed expenses (CFM, berseem, berseem hay and straw), and non-feed expenses (wages of permanent and hired labor, veterinary services and ear tags). While, revenues represent the sales of weaned lambs (on a live-weight basis), culled rams and ewes, wool and manure. Gross margin per ewe joined (GM/EJ) was used to indicate the relative profitability of the current Barki flock on the basis of per ewe where, $\mathrm{GM} / \mathrm{EJ}=$ (Revenues - variable costs) dividing by flock size (FAO, 2002). Gross margin per ewe joined was estimated according to the following static deterministic bio-economic model (FAO, 2002):

$\mathrm{GM} / \mathrm{EJ}=$

$$
\left(\sum_{i=1}^{3} R S A_{i}+\sum_{i=1}^{3} R S M_{i}+\sum_{i=1}^{3} R S W_{i}-\sum_{i=1}^{3} C M_{i}-\sum_{i=1}^{3} C F_{i}-\sum_{i=1}^{3} C V_{i}-\sum_{i=1}^{3} C W S_{i}\right)
$$

divided by flock size

Where, the sum $\sum_{i=1}^{3}$ refer to each of the three categories; lambs, culled rams and culled ewes; RSA 
are the revenues from sale of live animals; RSM are the revenues from the sale of manure; RSW are the revenues from the sale of wool; $\mathrm{CM}$ are the cost of management; $\mathrm{CF}$ are the cost of feed; $\mathrm{CV}$ are the cost of veterinary services, and CWS are the cost of wool shearing.

Economic values for the considered biological traits were calculated according to the following equation as suggested by Ponzoni (1988)

$\mathrm{EV}=\mathrm{GM} / \mathrm{EJ}-\mathrm{GM} / \mathrm{EJ}$

Where, $\mathrm{EV}$; is the economic value, GM'/EJ; is the gross margin per ewe joined after increase one unit, $\mathrm{GM} / \mathrm{EJ}$; is the gross margin per ewe joined of the base flock

\section{Sensitivity test:}

Sensitivity test is a part of economical analysis; testing the enterprise cash flow sensitivity to alternative proposals and identify which variables are causing the largest deviations from expectations (Barnard and Nix, 1993). Some of these unexpected variables are biological parameters of sheep flock, as well as, the market prices that are subject to variations from time to time. Thus, the current study proposed different scenarios to investigate possible changes on the predicted economic values of the obtained biological CCPs. The predicted EVs were evaluated in case of; increase lambing rate by $5 \%$, increase twinning rate by $2 \%$ and increase lamb mortality rate by $5 \%$ over the current biological parameters of the base flock. While the market prices were evaluated as 1.25 times the sale price of one $\mathrm{kg}$ of weaned lambs and as 1.25 times the cost of concentrate feed mix over the prevailing current market prices.

\section{RESULTS AND DISCUSSION}

\section{Flock biological performance}

The least squares means and standard deviation of the biological traits derived from the base run for the 37 breeding seasons of the studied Barki sheep flock are presented in Table (1). These results indicated that estimates obtained lie within the range of estimates reported for Barki breed in the previous literature (Ahmed (2008), El-Wakel et al., (2009), Mohammady (2014) and El-Wakel (2016)).

Table 1. Features of biological performance for the studied flock

\begin{tabular}{lcc}
\hline Variables & Least squares means & Standard deviation \\
\hline EL/EJ & 0.78 & 0.145 \\
LB/EL & 1.033 & 0.035 \\
KB/EJ $(\mathrm{kg})$ & 2.80 & 0.543 \\
KW/EJ $(\mathrm{kg})$ & 12.38 & 4.224 \\
BWT $(\mathrm{kg})$ & 3.49 & 0.184 \\
WWT $(\mathrm{kg})$ & 17.079 & 2.699 \\
LMR $(\%)$ & 20.6 & 0.116 \\
GR $(\mathrm{kg})$ & 0.171 & 0.032 \\
\hline
\end{tabular}

EL/EJ; number of ewes lambed per ewe joined, LB/EL; number of lambs born per ewe lambed, KB/EJ; kilograms of lambs born per ewe joined, KW/EJ; kilograms of lambs weaned per ewe joined, BWT; average birth weight, WWT; average weaning weight, LMR; lambs mortality rate up to weaning and GR; average growth rate from birth up to weaning age

\section{Partial correlation matrix:}

The partial correlation matrix among the studied biological variables is presented in Table (2). It could be observed that all obtained estimates of correlation coefficients among variables were significantly different from zero $(\mathrm{P}<0.05)$. The partial correlation coefficients among the dependent (KW/EJ) and other biological independent variables were moderate and ranged from -0.645 up to +0.727 . There is a positive correlation between the biological traits (EL/EJ,
LB/EL, BWT, WWT, GR and KB/EJ) and KW/EJ of the studied flock and ranged from 0.304 up to 0.727 . In contrary, lambs mortality rate appeared negative correlation of estimate -0.645 . The highest positive correlation coefficient was found between $\mathrm{KW} / \mathrm{EJ}$ and $\mathrm{KB} / \mathrm{EJ}$ of moderate estimate +0.727 , while the lowest correlation was found between $\mathrm{KW} / \mathrm{EJ}$ and BWT (+0.304).

Table2. Correlation matrix among the studied biological variables

\begin{tabular}{|c|c|c|c|c|c|c|c|c|}
\hline Variables & EL/EJ & LB/EL & BWT & WWT & LMR & GR & KB/EJ & KW/EJ \\
\hline EL/EJ & & 0.105 & -0.072 & 0.113 & -0.083 & 0.017 & 0.949 & 0.588 \\
\hline $\mathrm{LB} / \mathrm{EL}$ & & & -0.065 & -0.094 & -0.261 & 0.251 & 0.263 & 0.444 \\
\hline BWT & & & & 0.498 & -0.222 & 0.573 & 0.186 & 0.304 \\
\hline WWT & & & & & -0.187 & 0.680 & 0.223 & 0.391 \\
\hline LMR & & & & & & -0.274 & -0.181 & -0.645 \\
\hline GR & & & & & & & 0.214 & 0.595 \\
\hline $\mathrm{KB} / \mathrm{EJ}$ & & & & & & & & 0.727 \\
\hline
\end{tabular}

EL/EJ; number of ewes lambed per ewe joined, LB/EL; number of lambs born per ewe lambed, KB/EJ; kilograms of lambs born per ewe joined, KW/EJ; kilograms of lambs weaned per ewe joined, BWT; average birth weight, WWT; average weaning weight, LMR; lambs mortality rate up to weaning and GR; average growth rate from birth up to weaning age. 


\section{Variable important for prediction:}

Wold (1995) and Ericksson et al., (2001) suggested a bar chart of VIP; each bar represents one independent variable. Two border lines for the VIP values were plotted to identify the VIPs that are higher than 0.8 and 1 as shown in figure (1). These thresholds allow identifying the importance of the variable on the prediction equation. The current VIPs values pointed out that biological traits $\mathrm{KB} / \mathrm{EJ}$, LMR, GR and EL/EJ were the highly influential variables $(\mathrm{VIP}>1.0)$ on the prediction of $\mathrm{KW} / \mathrm{EJ}$. While, $\mathrm{LB} / \mathrm{EL}$ considered as a moderate influential variable
$(0.8<$ VIP $<1.0)$. On the other hand, WWT and BWT variables were non significant in the prediction equation. In the same context, KB/EJ was not considered due to biological limit of the trait. The obtained $\mathrm{R}^{2}$ among the biological variables was 0.91 that considered a satisfactory predictive power of multivariate regression. The obtained prediction equation generated from PLS procedures and applied to predict $\mathrm{KW} / \mathrm{EJ}$ was as follows:

$\mathrm{KW} / \mathrm{EJ}=-7.16+7.57 \mathrm{xEL} / \mathrm{EJ}+28.46 \mathrm{xLB} / \mathrm{EL}+0.54 \mathrm{x} \quad \mathrm{BWT}$ +0.10 x WWT-14.27x LMR+31.84x GR+2.38 x KB/EJ.

(4)

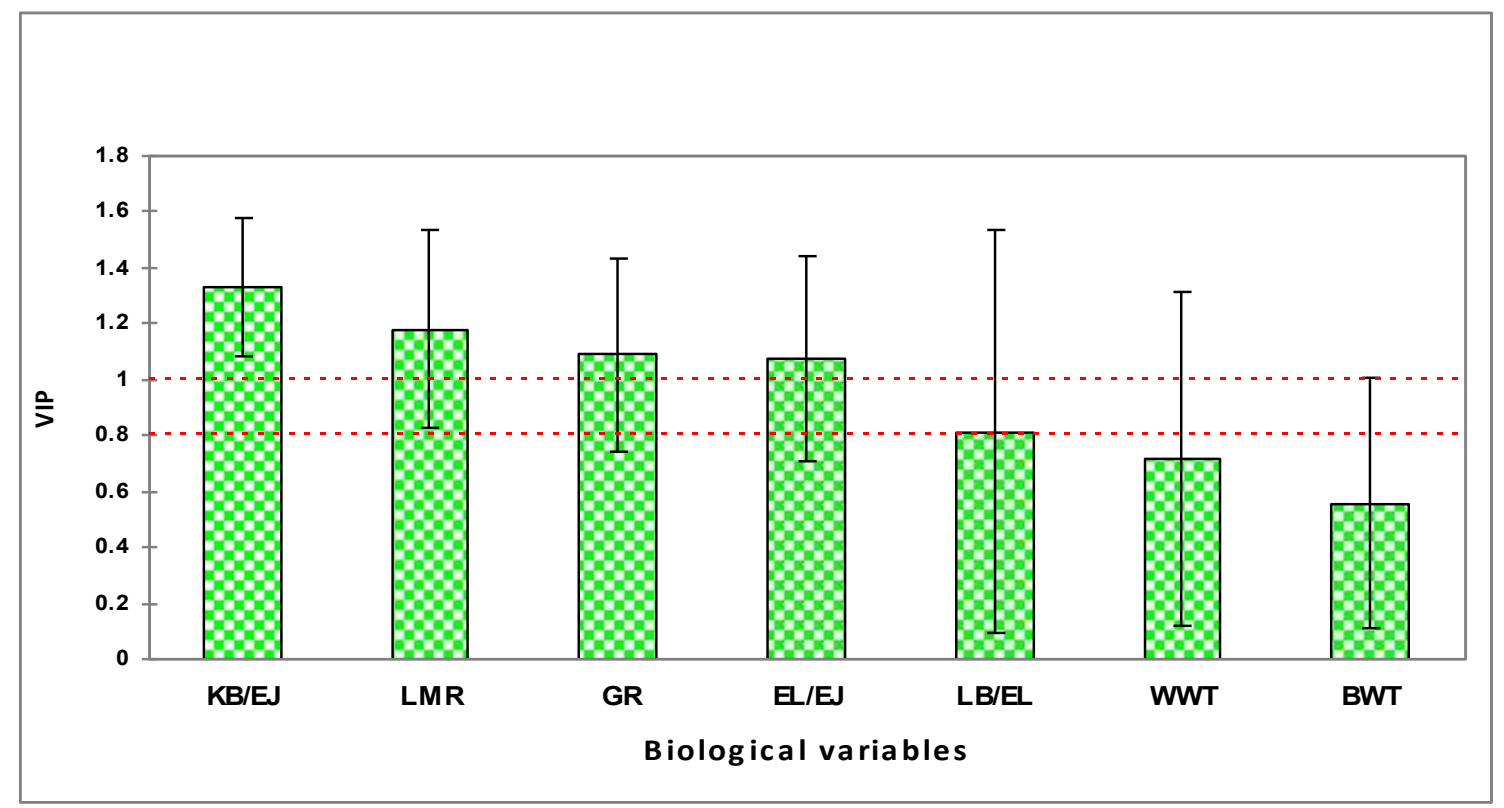

Figure 1. Variable important for prediction derived from Partial least squares regression.

\section{Biological values:}

The prospective change in $\mathrm{KW} / \mathrm{EJ}$ and the predicted biological values of the considered biological traits are displayed in Table (3). The obtained findings indicated that GR was the most effective control point on the KW/EJ. There was a marked positive increase in $\mathrm{KW} / \mathrm{EJ}$ with biological value of +548 gm over the base flock. This could be attributed to the positive impact of GR on the weight of lambs at weaning compared to the base flock. In this context, the contribution of EL/EJ and LB/EL followed the same positive trend as GR, however, it were achieved lower biological values of $+76 \mathrm{gm}$ and +285 gm, respectively. The recent result is lower than the corresponding estimate reported by Ahmed (2008) of biological values of $+300 \mathrm{gm}$ for EL/EJ, while the current $\mathrm{LB} / \mathrm{EJ}$ is higher than that reported by Ahmed (2008) of +270 gm of the same breed. On the contrary, LMR plays an obvious negative effect on $\mathrm{KW} / \mathrm{EJ}$ and declined KW/EJ by $-143 \mathrm{gm}$. This could be as a result of lower number of lambs weaned per ewe joined compared to the base flock. The current result is lower than that obtained by Ahmed (2008) of -220 gm. These finding comes in agreement with that reported by Nudell et al. (1998) who confirmed that death loss in lambs is identified in the subset of critical control points.

Table 3. Predicted biological values of the considered biological traits for the studied Barki flock

\begin{tabular}{lcc}
\hline Traits & KW/EJ & Biological Values (gm) \\
\hline Base flock & 12.53 & +76 \\
EL/EJ $(+1 \%)$ & 12.61 & +285 \\
LB/EL $(+1 \%)$ & 12.81 & -143 \\
LMR $(+1 \%)$ & 12.39 & +548 \\
GR $(+10 \%)$ & 13.08 & \\
\hline
\end{tabular}

EL/EJ; number of ewes lambed per ewe joined, LB/EL; number of lambs born per ewe lambed, KW/EJ; kilograms of lambs weaned per ewe joined, LMR; lambs mortality rate up to weaning and GR; average growth rate from birth up to weaning age. 


\section{Economic values:}

The predicted economic values of the considered biological traits derived from bio-economic model are displayed in Table (4). The base flock showed that each ewe joined the mating season achieved GM of LE 291 under the current management practices. Results declared that changes the biological traits by one unit had a different impact on expected GM/EJ. The positive impact was observed for EL/EJ LB/EL and GR. Growth rate had the highest positive EV per ewe among all the studied biological traits and exceeded GM by LE +25 compared to base flock. Opposite trend was noticed for lambs' mortality rate which had negative EV of LE -6 . The results are in agreement with that reported by Morais and Madalena (2006) and Lobo et al., (2011). In this context, LB/EL showed intermediate economic value $(\mathrm{LE}+13)$. This results was in the same trend that reported by Rahimi et al. (2015) who showed that growth rate from birth to weaning and litter size had intermediate economic value of MU 0.81 and $\mathrm{MU}$ 0.39 for Makui sheep, respectively. Results revealed that death losses had a negative impact on flock profitability, since most death in lambs occurs in the first three days of life when they are in lambing barn (Ringwall et al. 1994). From economic point of view, the current findings identified that GR and LMR are the critical control points for Barki flock profitability. Moreover, GR considered a critical success factor in the revenues, while LMR considered a losses one.

Table 4. Predicted economic values of the considered biological traits for the studied Barki flock

\begin{tabular}{lcc}
\hline Traits & GM/EJ & Economic values (LE) \\
\hline Base flock & 291 & +2 \\
EL/EJ $(+1 \%)$ & 293 & +13 \\
LB/EL $(+1 \%)$ & 304 & -6 \\
LMR $(+1 \%)$ & 285 & +25 \\
GR $(+10 \%)$ & 316 & ( $1 \%$ )
\end{tabular}

GM/EJ; gross margin per ewe joined, EL/EJ; number of ewes lambed per ewe joined, LB/EL; number of lambs born per ewe lambed, KW/EJ; kilograms of lambs weaned per ewe joined, LMR; lambs mortality rate up to weaning and GR; average growth rate from birth up to weaning age.

\section{Sensitivity analysis:}

Results of sensitivity analysis for the proposed scenarios are presented in Table (5). The changes in biological parameters and market price indicators showed different responses on the economic values of the studied biological traits. Some of these indicators had a positive impact and improve the economic value of the trait, while the others had a negative one and decrease the EV. Changes EL/EJ, LB/EL, GR and lambs selling price showed a positive impact on all the studied traits. Furthermore, sensitivity analysis declared that, EVs of all the studied traits are more sensitive in negative direction to changes in CFM price and lambs mortality than the other proposed scenarios.

Table 5. Impact of the proposed scenarios on the economic values of biological traits

\begin{tabular}{lccccc}
\hline \multirow{2}{*}{ Proposed scenarios } & \multicolumn{4}{c}{ Biological traits } & \multirow{2}{*}{ Total GM } \\
\cline { 2 - 4 } & EL/EJ & LB/EL & LMR & GR & 56250 \\
Economic values & +2 & +13 & -6 & +25 & 58911 \\
EL/EJ (+5\%) & $+8.5 \%$ & $+0.9 \%$ & $-1.3 \%$ & $+0.5 \%$ & 63438 \\
LB/EL (+2\%) & $+18.8 \%$ & $+1.2 \%$ & $-4.4 \%$ & $+0.1 \%$ & 48583 \\
LMR (+5\%) & $-25.9 \%$ & $-3.7 \%$ & $+3.3 \%$ & $-2.4 \%$ & 63157 \\
GR (+5\%) & $+8.5 \%$ & $+0.1 \%$ & $-2.6 \%$ & $-0.5 \%$ & 61960 \\
Selling price (+5\%) & $+20.9 \%$ & $+1.5 \%$ & $-4.7 \%$ & $+0.3 \%$ & 40895 \\
CFM (+25\%) & $-59.3 \%$ & $-7.6 \%$ & $-11.3 \%$ & $-2.3 \%$ & \\
\hline
\end{tabular}

GM/EJ; gross margin per ewe joined, EL/EJ; number of ewes lambed per ewe joined, LB/EL; number of lambs born per ewe lambed, LMR; lambs mortality rate up to weaning and GR; average growth rate from birth up to weaning age, CFM; concentrate feed mix.

\section{CONCLUSION}

It is of interest to conclude that ranking in descending order of the biological values of the considered biological traits are in harmony with its corresponding economic values. The current findings provided evidence that growth rate and mortality rate traits are the most biological critical control points for Barki flock productivity and profitability. From economic point of view, it is clear to notice that, GR considered a critical success factor in the revenues, while LMR had a severe negative impact on Barki sheep enterprise profitability. Thus, due to the attained results, GR and LMR should be the highest priority for further research. In addition, sensitivity analysis confirmed that, EVs of the studied traits were more sensitive to changes in CFM costs and LMR than the other proposed scenarios. Further researches are needed in this field to identify the economical CCPs for Barki sheep enterprise.

\section{ACKNOWLEDGMENT}

The author expresses her sincere appreciation to the Animal Breeding Unit, Department of Animal 
Breeding of Desert Research Center for supporting and providing breeding flock data.

\section{REFERENCES}

Ahmed, A.M., 2008. Technical and financial analysis of Barki sheep under semi-intensive production system. Egyptian J. Anim. Prod., 45 (1): 25-34

Barnard, C.S., J.S. Nix, 1993. Farm Planning and Control, $2^{\text {nd }}$ Edition. Cambridge University Press, Cambridge.

CAPMAS, 2015. Egypt's Central Agency for Public Mobilization and Statistics. http://www.capmas.gov.eg.

El-Wakel, Salwa, I., Manal El-Sayed, A.M. Ahmed, R.R. Sadek, and A.A. Nigm, 2009. Genetic and phenotypic parameters of birth, weaning and yearling body weights of Barki sheep raised in the North Western Coast of Egypt. Egyptian J. Anim. Prod., 46 (2): 43-52

El-Wakel, Salwa I., 2016. Layers of Open Nucleus breeding scheme in relation to the genetic improvement of weaning weight in Barki sheep: A simulation study. Egyptian J. Anim. Prod., 53 (1): $35-42$

Ericksson, L., E. Johansson, N. Kettaneh-Wold, and S. Wold, 2001. Multi-and Megavariate Data Analysis. Principals and Applications, Umetrics Academy, Umea.

FAO, 2002. Production Systems in the Near East Region. A Training Manual for Characterization and Analysis. Food and Agriculture Organization

Lobo, R.N.B., I.D.C. Pereira, O. Faco, and C.M. McMacus. 2011. Economic values for production traits of Morada Nova meat sheep in a pasture based production system in semi-arid Brazil. Small Ruminant Research 96: 93-100

Mohammady, Mona, I., 2014. Influence of flock size and biological performance on economic efficiency of Barki sheep under semi-arid conditions in Egypt. Journal of American Science. 10 (3s): 73-79
Morais, O.R., and F.E. Madalena, 2006. Economic values for production traits in Santa Ines sheep. $8^{\text {th }}$ World Congress on Genetics Applied to Livestock Production, August 13-18, 2006, Belo Horizonte, MG, Brasil

Nudell, D., H. Hughes, and T. Faller, 1998. Critical control points for profitability in sheep production. North Dakota Agricultural Research, North Dakota State University. http://www.ag.ndsu.nodak.edu/ndagres/fall98/ar1 1198.htm (3 of 13) [2/10/2010 1:25:22 PM]

Rahimi, S.M., S.A. Rafat, J. Shoja, and S. Alijani, 2015. Calculating economic weights for growth, reproduction and wool traits in Makui sheep breed by Ecoweight Software. Biotechnology in Animal Husbandry 31 (1), p 63-72, 2015 ISSN 1450-9156 Publisher: Institute for Animal Husbandry, Belgrade-Zemun

Ponzoni, R. W., 1988. The derivation of economic values combining income and expense in different ways: An example with Australian Merino sheep. J.Anim. Breed. Genet.105:143-153

Ringwall, K.A., P.M. Berg, T.C. Faller, P.L. Marek, and J.W. Galbreth, 1994. Understanding the Components of Sheep Reproduction, $35^{\text {th }}$ Annual Western Dakota Sheep Day Report.

SAS, 2004. SAS Statistics. Guide Release Edition. SAS Inst., Inc., Cary, NC.

Tibbo M., J., Philipsson, and W., Ayalew, 2006. Sustainable sheep breeding programmes in the tropics: a framework for Ethiopia. Conference on International Agricultural Research for Development. University of Bonn, October 1113, 2006

Wold, S., 1995. PLS for multivariate linear modeling. In: van de Waterbeemd H. (ed.), QSAR: Chemometric Methods in Molecular Design. Vol. 2 Wiley-VCH, Weinheim, Germany, 195-218.

XLSTAT, 2009. Statistical software for MS ExcelStatistics and data analysis with MS Excel Addinsoft, 224 Centre Street, $3^{\text {rd }}$ Floor, New York, NY 10013 USA.

\section{تحديد بعض نقاط التحكم البيولوجية الحرجة فى إنتاج الأغنام البرقى المرباة فى صحراء الساحل الثمالى الغربى بمصر

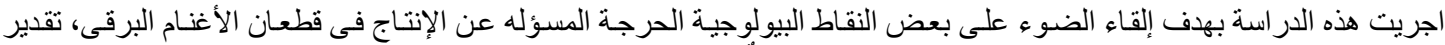

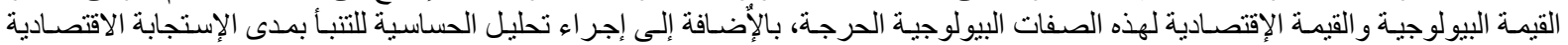

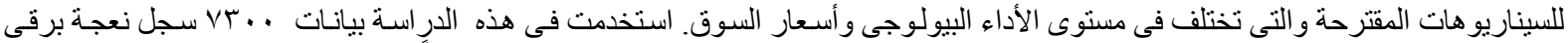

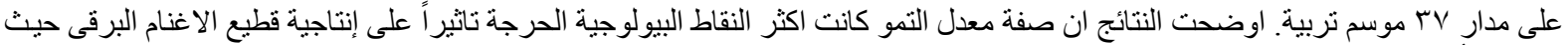

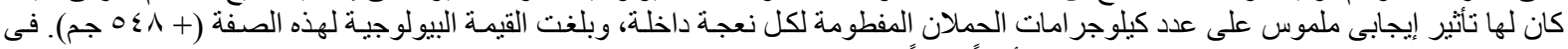

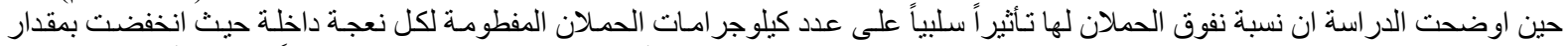

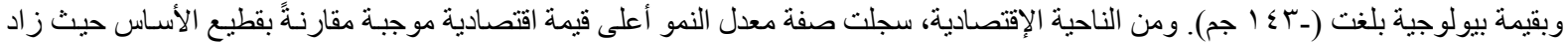

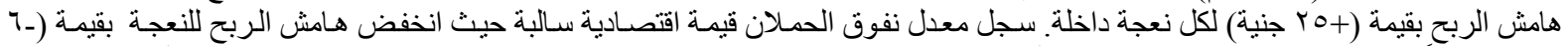

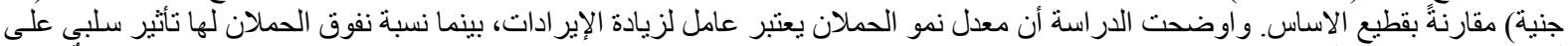

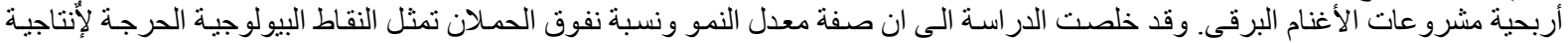

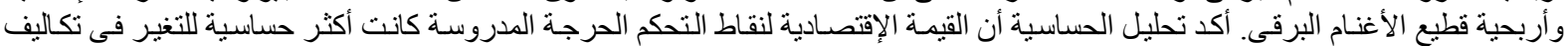
العلف المركز وكذلك نسبة نفوق الحملان عن باقى السيناريو هات العين المقترحة. 